\title{
Bronconeumonitis por virus herpes simple en paciente con fallo respiratorio postoperatorio
}

\author{
M. García-Montesinos-De la Peña*, L. Oteiza-López, S. Aldunate-Calvo, \\ M.J. Gómez-Sánchez, J.J. Sáenz-Bañuelos y J.A. Tihista-Jiménez
}

Servicio de Medicina Intensiva, Hospital Virgen del Camino, Pamplona, Navarra, España

Recibido el 13 de febrero de 2009; aceptado el 15 de abril de 2009

Disponible en Internet el 2 de octubre de 2009

\section{PALABRAS CLAVE \\ Virus herpes simple; \\ Infección viral; \\ Cuidados intensivos; \\ Bronconeumonía; \\ Inmunocompetencia}

\section{KEYWORDS}

Herpes simplex virus;

Viral infection;

Intensive care;

Bronchopneumonia;

Immunocompetence

\begin{abstract}
Resumen
La bronconeumonitis por virus herpes simple (VHS) es una entidad clínica descrita en pacientes críticos, asociada clásicamente a estados de inmunosupresión. Estudios recientes han demostrado una elevada frecuencia de detección del virus en muestras del tracto respiratorio inferior (obtenidas por lavado broncoalveolar [BAL]) de pacientes críticos inmunocompetentes ventilados mecánicamente, lo que indicaría su papel como sustrato patogénico independiente.

Presentamos el caso de una paciente que ingresa tras intervención quirúrgica de neoplasia de recto, con sospecha de broncoaspiración durante la inducción anestésica. Presenta evolución clínica marcada por fiebre persistente pese a tratamiento antibiótico de amplio espectro, ausencia de crecimiento bacteriano en los cultivos obtenidos, sin claros infiltrados radiológicos y ventilación mecánica prolongada con reiterados fracasos en el destete, y que precisa traqueostomía percutánea. Se realiza broncoscopia con BAL y se detecta VHS (a nivel microbiológico e histológico), por lo que se inicia tratamiento con aciclovir con mejoría clínica y retirada del soporte ventilatorio.

(c) 2009 Elsevier España, S.L. y SEMICYUC. Todos los derechos reservados.
\end{abstract}

Herpes simplex virus bronchopneumonitis in patient with acute respiratory failure after surgery

\begin{abstract}
Herpes simplex virus bronchopneumonitis is a clinical entity described in critically ill patients and classically associated to immunosuppression. Recent reports have shown a higher frequency of virus detection from samples obtained by bronchoalveolar lavage of immunocompetent critically ill patients undergoing mechanical ventilation. This fact suggests its role as an independent pathogenic substrate.
\end{abstract}

*Autor para correspondencia.

Correo electrónico: manolillou@yahoo.es (M. García-Montesinos-De la Peña). 
We report the case of a female patient who was admitted after an elective surgery of rectal tumor with suspected bronchoaspiration during anesthetic induction. The patient presented persistent fever despite broad spectrum antibiotic treatment. All cultures were negative for bacterial growth. The chest X-ray did not show opacifities. Prolonged mechanical ventilation with repeated failures to wean made it mandatory to perform percutaneous tracheostomy. A fibrobronchoscopy with bronchoalveolar lavage, performed previously, showed positive result for herpes simplex virus (PCR and specific nuclear inclusions in cells). Thus, treatment was initiated with acyclovir, with clinical improvement and weaning from mechanical ventilation.

(c) 2009 Elsevier España, S.L. and SEMICYUC. All rights reserved.

\section{Introducción}

Las infecciones respiratorias nosocomiales de origen viral están emergiendo y su frecuencia de detección en pacientes críticos está aumentando gracias a los nuevos métodos de diagnóstico rápido (reacción en cadena de la polimerasa [PCR] en tiempo real). El Herpesviridae causa la mayor parte, y destaca por su frecuencia el virus herpes simple (VHS) y el citomegalovirus (CMV). El VHS-1 se aísla hasta en el $5 \%{ }^{1}$ del tracto respiratorio de adultos asintomáticos, y asciende a un $22 \%$ en pacientes ingresados en $\mathrm{UCl}^{2}$ y hasta un $41 \%$ en pacientes postquirúrgicos ${ }^{3}$. Hay que tener en cuenta a la hora de valorar estas cifras que la detección del virus no implica necesariamente infección viral activa y, por tanto, es crucial distinguir portadores asintomáticos de pacientes con infección sintomática. La forma clínica de presentación más común del VHS-1 es la afección mucocutánea y, más raramente, la infección del sistema nervioso central. La infección pulmonar es extremadamente rara, salvo en inmusuprimidos graves ${ }^{4,5}$. Aparte de las causas más generales de inmunosupresión, como es el tratamiento inmunosupresivo, se ha visto que otras situaciones, como cirugía mayor $^{6-9}$, trauma ${ }^{10}$ y hemorragia importante, podrían causar un descenso crítico en la inmunidad celular y facilitar la reactivación del virus.

Presentamos el caso de una mujer con ventilación mecánica (VM) y fracaso reiterado en el destete atribuible a una bronconeumonitis por VHS-1.

\section{Caso clínico}

Se trata de una mujer de 70 años con antecedentes de HTA y diagnosticada recientemente de neoplasia de recto bajo, tratada con quimioterapia (análogo del 5-fluorouracilo) y radioterapia preoperatoria terminada 2 meses antes de la cirugía. Ingresa en UCl tras intervención quirúrgica (amputación abdominoperineal) por sospecha de broncoaspiración durante la inducción anestésica con repercusión oximétrica y dificultades ventilatorias. Se encuentra sedoanalgesiada, intubada y conectada a VM. A nivel radiológico no se observan infiltrados indicativos de afectación pulmonar parenquimatosa. Tiene una buena evolución inicial, por lo que se la extuba sin incidencias a las $48 \mathrm{~h}$. Presenta empeoramiento progresivo en los siguientes 2 días a nivel radiológico (afectación parenquimatosa basal derecha), gasométrico (se precisó ventilación mecánica no invasiva (VMNI) para mantener la pulsioximetría a más del 90\%) y clínico (taquipnea persistente con mala mecánica respiratoria), por lo que se la reintuba. Comienza con fiebre superior a $39{ }^{\circ} \mathrm{C}$ persistente, resistente a antitérmicos y medidas físicas. Se extraen muestras microbiológicas (hemocultivo, urocultivo y broncoaspirado). Se mantiene el tratamiento antibiótico iniciado en el quirófano. A nivel analítico destaca reacción inflamatoria importante con proteína $C$ reactiva de $50 \mathrm{mg} / \mathrm{dl}$ sin acompañarse de reacción leucocitaria $\left(<10.000 \times 10^{3} / \mu \mathrm{l}\right)$. Se mantiene intubada y conectada a VM 7 días durante los que persiste la fiebre con picos mayores de $39^{\circ} \mathrm{C}$, con mejoría radiológica sin infiltrados y muestras microbiológicas negativas persistentemente; se realiza TC abdominal y se descarta complicación derivada de la cirugía. Se extuba a la paciente afebril, con gasometría compensada y buena respuesta a las pruebas respiratorias espontáneas; a pesar de las condiciones óptimas en el momento de extubación, se la tiene que reintubar en $12 \mathrm{~h}$ por fracaso respiratorio. Nuevamente comienza con fiebre elevada y con cultivos reiterados negativos, por lo que se realiza fibrobroncoscopia con recogida de lavado broncoalveolar (BAL) y se mandan muestras a microbiología (cultivo y PCR para herpes, CMV y virus respiratorios) y anatomía patológica. Se realiza traqueostomía percutánea y se reciben los resultados del $\mathrm{BAL}$, en los que se constata PCR VHS-1 positivo precoz (test cualitativo) y, a nivel histológico, presencia de células que muestran núcleos multinucleados (fig. 1), con cromatina en vidrio esmerilado e inclusiones intranucleares (fig. 2); inmunocitoquímicamente se constata positividad nuclear para herpes virus. Se inicia tratamiento antiviral con aciclovir $10 \mathrm{mg} / \mathrm{kg} / 8 \mathrm{~h}$ i.v. con mejoría clínica, desaparición de la fiebre y desconexión progresiva del respirador hasta su autonomía respiratoria plena.

\section{Discusión}

El caso clínico que presentamos viene a incidir en la importancia del análisis del significado clínico del aislamiento de VHS-1 en muestras del tracto respiratorio inferior de pacientes críticos. Clásicamente, la infección pulmonar por VHS-1 se ha asociado a estados de inmusupresión grave, tanto por administración sistémica (corticoides, inmunosupresores, radioterapia o quimioterapia) como por factores que producen daño local, promueven la metaplasia escamosa del epitelio respiratorio —entre ellos la creación de una vía aérea artificial, trauma o humo-y facilitan con la disrupción del epitelio la reactivación viral ${ }^{11,12}$. En 


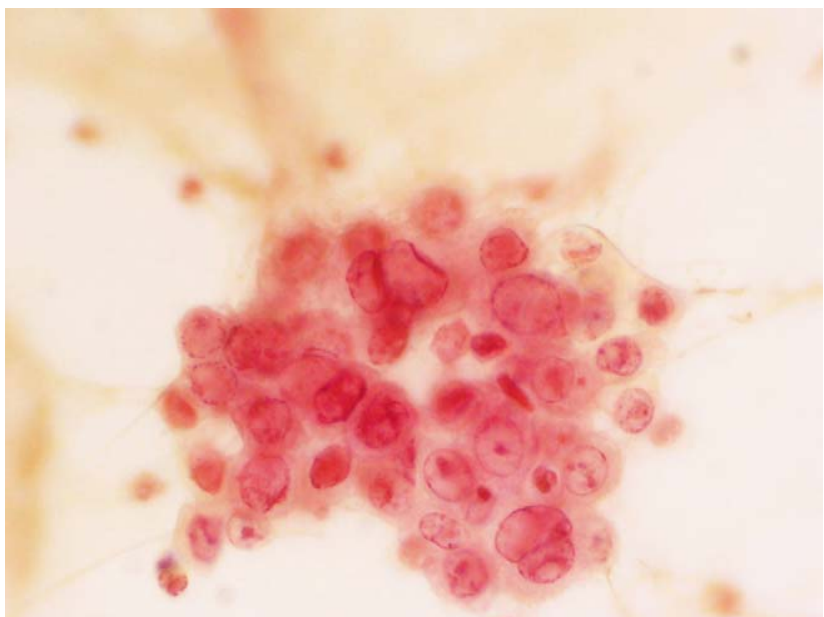

Figura 1 Tinción Perls $(40 \times)$. Células bronquiales gigantes multinucleadas con inclusiones intranucleares, típicas de la infección por virus herpes simple.

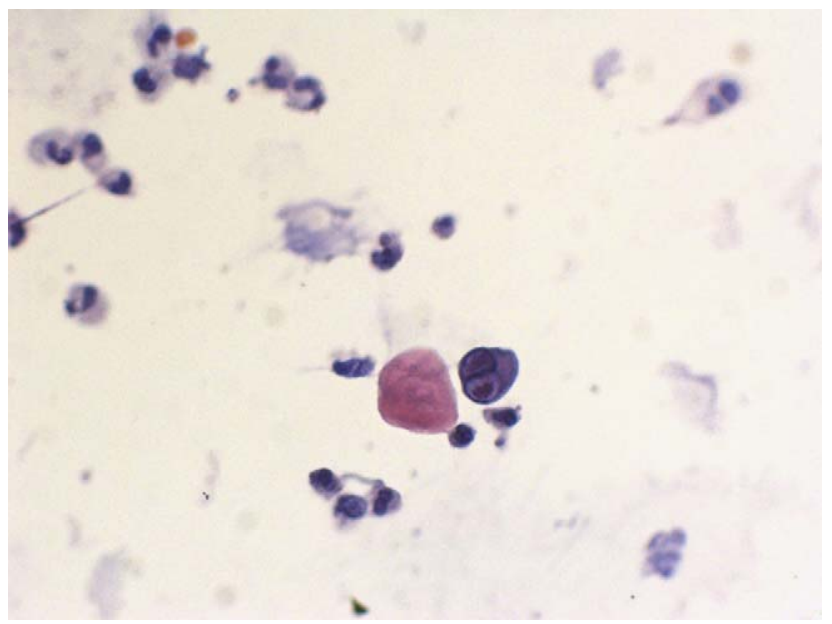

Figura 2 Tinción de Papanicolaou $(40 \times)$. En el centro de la imagen se puede observar una célula bronquial con los cambios citopáticos característicos de virus herpes simple: cromatina en vidrio esmerilado e inclusiones intranucleares.

estudios post mórtem se ha detectado VHS por tinción inmunohistoquímica en muestras de tejido pulmonar procedente de pacientes quemados, con distress respiratorio y postquirúrgicos ${ }^{13,14}$. Sin embargo, modelos animales, reportes de casos y estudios pilotos han mostrado que la infección pulmonar por VHS-1 no está ligada exclusivamente a estados de inmunosupresión $7,11,15$. No sólo eso, sino que 2 trabajos recientes con gran número de pacientes críticos han detectado VHS-1 en pacientes no considerados inicialmente como inmunosuprimidos y se estableció su patogenia en la evolución clínica respiratoria ${ }^{2,16,17}$.

El cuadro clínico de la reactivación del VHS-1 varía desde formas asintomáticas hasta úlceras labiales, gingivoestomatitis y, en los casos más graves, infección respiratoria manifestada como disnea inexplicable, fiebre, broncoespasmo, fracaso en el weaning, hipoxemia sin infiltrados pulmonares radiológicos o alteraciones gasométricas.
A nivel del diagnóstico por imagen se describen todo tipo de patrones de presentación radiológica independientemente del estado inmunitario, desde normalidad del parénquima pulmonar hasta condensaciones pulmonares de localización lobular o más extensa y siempre de forma bilateral, infiltrados intersticiales 0 infiltrados mixtos ${ }^{18}$.

En cuanto al diagnóstico, la dificultad radica en que no existen criterios clínicos ni de laboratorio universalmente establecidos para diagnosticar la bronconeumonitis por VHS1. Tanto es así que existen en la literatura médica reciente varias publicaciones dirigidas en este sentido. En el trabajo de Luyt et $\mathrm{al}^{19}$, prospectivo, observacional, con 201 pacientes inmunocompetentes con VM prolongada y con sospecha de neumonía asociada a ventilación (NAV), se diagnosticaron 42 (21\%) bronconeumonitis por VHS-1, definida como deterioro clínico que conlleva realización de fibrobroncoscopia con BAL, asociado a la detección de VHS-1 en el líquido del BAL (por PCR, cultivo o ambos) e inclusiones nucleares VHS específicas en las células del BAL. Usando un punto de corte de carga viral por PCR en $10^{4}$ copias $/ 10^{6}$ células presentes en BAL, se obtiene una sensibilidad del $81 \%$ y una especificidad del $83 \%$ para el diagnóstico de bronconeumonitis. Linssen et $\mathrm{al}^{10}$ realizaron un análisis restrospectivo de muestras de BAL efectuadas durante un período de 5 años y solicitadas por sospecha de NAV o infección vírica respiratoria, y analizaron la carga viral del VHS por PCR. Encontraron que las cargas virales mayores a $10^{5}$ ge (equivalentes genómicos) $/ \mathrm{ml}$ se asocian a un aumento de mortalidad hospitalaria a los 14 días del $21 \%$ respecto a los pacientes con cargas menores o iguales a $10^{5}$ ge en pacientes con más de $48 \mathrm{~h}$ de estancia hospitalaria. Infirieron que una carga viral mayor a $10^{5} \mathrm{ge} / \mathrm{ml}$ en $\mathrm{BAL}$ es altamente indicativa de infección pulmonar activa y debería considerarse su tratamiento. En un reciente estudio de Aisenberg et $\mathrm{al}^{20}$ se realizó un análisis retrospectivo de la presencia de VHS aislado en muestras del tracto respiratorio inferior de pacientes con tumores sólidos con el objetivo de analizar la relevancia clínica del cultivo VHS positivo, con o sin efecto citopático, en pacientes con clínica y hallazgos radiológicos compatibles con infección pulmonar viral. Clasificaron a los pacientes como infección pulmonar probada (cultivo y citología positivos), probable (sólo cultivo VHS positivo y como único patógeno) y posible (cultivo VHS positivo acompañado de otros patógenos). Demostraron que los pacientes con infección pulmonar por VHS-1 probada se asocian a mayor morbilidad (expresada en términos de mayor estancia en $\mathrm{UCl}$ y mayores tiempos de VM) pero no existe impacto en la mortalidad. Estos pacientes podrían beneficiarse del tratamiento antiviral.

En resumen, la bronconeumonitis por VHS-1 es una entidad clínica cuya incidencia en pacientes críticos inmunosuprimidos e inmunocompetentes está aumentando y que en la actualidad permanece sin criterios diagnósticos consensuados, por lo que la indicación de tratamiento es hoy en día objeto de controversia. De esta manera, se postula como una entidad más para tener en cuenta a la hora de enfrentarse a pacientes críticos con VM cuyo tratamiento debe ser individualizado según clínica, factores de riesgo, datos y muestras de laboratorio, sin poder hoy en día establecer de forma clara qué pacientes se podrían beneficiar del tratamiento antiviral. 


\section{Agradecimientos}

Deseamos presentar nuestro agradecimiento a los Servicios de Microbiología y de Anatomía Patológica del Hospital Virgen del Camino por su colaboración en el proceso diagnóstico y la cesión de las imágenes citológicas.

\section{Bibliografía}

1. Cleator GM, Klapper PE. Principles and practice of clinical virology, 5 ed. London: Wiley; 2005.

2. Bruynseels P, Jorens PG, Demey HE, Goossens H, Pattyn SR, Elseviers $M M$, et al. Herpes simplex virus in the respiratory tract of critical care patients: A prospective study. Lancet. 2003;362:1536-41.

3. Porteus C, Bradley JA, Hamilton DN, Ledingham IM, Clements $\mathrm{GB}$, Robinson CG. Herpes simplex virus reactivation in surgical patients. Crit Care Med. 1984;12:626-8.

4. Tang IT, Shepp DH. Herpes simplex virus infection in cancer patients: Prevention and treatment. Oncology (Willinston Park). 1992;6:101-6 109; discussion 109-110.

5. Nichols WG, Boeckh M, Carter RA, Wald A, Corey L. Transferred herpes simplex virus immunity after stem-cell transplantation: Clinical implications. J Infect Dis. 2003;187:801-8.

6. Klainer AS, Oud L, Randazzo J, Freiheiter J, Bisaccia E, Gerhard $\mathrm{H}$. Herpes simplex virus involvement of the lower respiratory tract following surgery. Chest. 1994;106:8S-14S discussion 34S-35S.

7. Arata K, Sakata R, Iguro Y, Toda R, Watanabe S, Eitsuru Y. Herpes simples viral pneumonia after coronary artery bypass grafting. Jpn J Thorac Cardiovasc Surg. 2003;51:158-9.

8. Eisenstein LE, Cunha BA. Herpes simplex virus pneumonia presenting as a failure to wean from a ventilator. Heart Lung. 2003;32:65-6.

9. Linsenn CF, Jacobs JA, Stelma FF, Van Mook WN, Terporten P, Vink $C$, et al. Herpes simplex virus load in bronchoalveolar lavage fluid is related to poor outcome in critically ill patients. Intensive Care Med. 2008;34:2202-9.

10. Cherr GS, Meredith JW, Chang M. Herpes simplex virus pneumonia in trauma patients. J Trauma. 2000;49:547-9.

11. Hayden FG, Himel HN, Heggers JP. Herpesvirus infections in burn patients. Chest. 1994;106:15S-21S.

12. Graham BS, Snell Jr JD. Herpes simplex virus infection of the adult lower respiratory tract. Medicine (Baltimore). 1983;62: 384-393.

13. Byers RJ, Hasleton PS, Quigley A, Dennett C, Klapper PE, Cleator GM, et al. Pulmonary herpes simplex in burn patients. Eur Respir J. 1996;9:2313-17.

14. Cook CH, Yenchar JK, Kraner TO, Davies EA, Ferguson RM. Occult herpes family viruses may increase mortality in critically ill surgical patients. Am J Surg. 1998;176:357-60.

15. Miyazato A, Kashimoto H, Tamaki K, Nakama K, Saito A. Herpes simplex virus bronchopneumonia in a non-immunocompromized individual. Intern Med. 2001;40:836-40.

16. Ong GM, Lowry K, Mahajan S, Wyatt DE, Simpson C, O'Neill HJ, et al. Herpes simplex type 1 shedding is associated with reduced hospital survival in patients receiving assisted ventilation in a tertiary referral intensive care unit. J Med Virol. 2004;72:121-5.

17. Camp K, Jorens PG, Demey HE, Pattyn SR, leven M. Clinical significance of herpes simplex virus in the lower respiratory tract of critically ill patients. Eur J Clin Microbiol Infect Dis. 2002;21:758-9.

18. Umans U, Golding RP, Duraku S, Manoliu RA. Herpes simplex virus 1 pneumonia: Conventional chest radiograph pattern. Eur Radiol. 2001;11:990-4.

19. Luyt CE, Combes A, Deback CA, Aubriot-Lorton MH, Nieszkowska A, Trouillet JL, et al. Herpes simplex virus lung infection in patients undergoing prolonged mechanical ventilation. Am J Resp Crit Care Med. 2007;175:935-42.

20. Aisenberg G, Torres H, Terrand J, Safdar A, Bodey G, Chemaly RF. Herpes simplex virus lower respiratory tract infection in patients with solid tumors. Cancer. 2009;115:199-206. 